PAPER • OPEN ACCESS

Benefit of porous silica nanoreactor in preparation of fluorescence carbon dots from citric acid

To cite this article: Albina Mikhraliieva et al 2020 Nano Express 1010011

View the article online for updates and enhancements. 
CrossMark

OPEN ACCESS

RECEIVED

21 February 2020

REVISED

4 March 2020

ACCEPTED FOR PUBLICATION

9 March 2020

PUBLISHED

30 March 2020

Original content from thi work may be used under the terms of the Creative

Commons Attribution 4.0

licence.

Any further distribution of this work must maintain attribution to the author(s) and the title of the work, journal citation and DOI.

\title{
Benefit of porous silica nanoreactor in preparation of fluorescence carbon dots from citric acid
}

\author{
Albina Mikhraliieva ${ }^{(1)}$, Vladimir Zaitsev ${ }^{(1)}$, Ricardo Q Aucélio, Henrique B da Motta and \\ Michael Nazarkovsky (i) \\ Department of Chemistry, Pontifical Catholic University of Rio de Janeiro Marques de São Vicente, 225, 22451-900, Rio de Janeiro, Brasil \\ E-mail:vnzaitsev@puc-rio.br
}

Keywords: carbon dots, nanoreactor, citric acid, photoluminescence

Supplementary material for this article is available online

\begin{abstract}
A facile and robust synthesis of carbon dots (CDs) emitting blue-light in water without activation and stabilization has been developed by pyrolysis of citric acid (CA) adsorbed in silica gel $\left(\mathrm{SiO}_{2}\right)$ pores. Effect of the host pore size on luminescent properties of $\mathrm{SiO}_{2} @ \mathrm{CDs}$ nanocomposite as well as water suspension of CDs has been studied. The synthesis conditions such as concentration of the precursor, duration of synthesis also have been investigated. It has been demonstrated that upon the thermal treatment of silica gels saturated with CA $\left(60 \%\right.$ of maximum loading) at $170{ }^{\circ} \mathrm{C}$ for $5-600 \mathrm{~min}$, luminescent $\mathrm{CDs}$ are shaped inside the nanoreactor pores. These $\mathrm{SiO}_{2} @ \mathrm{CDs}$ emit photoluminescence centered at $450 \mathrm{~nm}$. Silica-immobilized CDs can be separated from the source molecules and sideproducts by centrifugation, which allows avoiding the dialysis of the resulted mixture and so improve the scaling of the synthesis. The CDs can be easily released from $\mathrm{SiO}_{2} @ \mathrm{CDs}$ by washing it with water. Water-eluted CDs demonstrate photoluminescence at $447 \mathrm{~nm}$. The smaller pore size of the host and longer time of thermal treatment promote the formation of the CDs with better photoluminescent peak symmetry and higher quantum yield up to $10.1 \%$.
\end{abstract}

\section{Introduction}

Carbon dots (CDs) are a unique new class of water-soluble nanoobjects with strong photoluminescence (PL) in the visible range. Unlike other known nanomaterials, such as noble metal nanoparticles, semiconductor quantum dots and hybrids of organic metal halides, CDs exhibit numerous advantages such as high photostability, low toxicity, and low cost. Finally, the production and application of CDs are very sustainable. They can be obtained from various organic objects and degrade in a natural environment to $\mathrm{CO}_{2}$. Due to their strong photoluminescence, non-toxic nature, good chemical stability, and biocompatibility CDs have great potential in energy conversion and storage [1], water disinfection [2], food safety [3] analytical chemistry [4-6] for development of chemical- and bio-sensors [6-8], biotechnology and nanomedicine [9-11] in cell imaging and biolabeling [12-15], for drug release [16], theranostics [9, 17], and photodynamic therapy [18], etc.

Carbon dots were first received in 2004 by the electrophoretic purification of oxidized single-wall carbon nanotubes [19]. Later, this approach was generalized as 'top-down' [20] and applied to graphite, graphene oxide [21] and nanodiamonds [22]. The top-down approach is based on the shredding of large carbon objects by using arc discharge [19], laser ablation [23], chemical or electrochemical oxidation [24]. The main problems of the top-down synthesis are low $\mathrm{CDs}$ yield and small quantum yield (QY) of photoluminescence for the resulting CDs. For example, CDs prepared from candle soot have QY about 2\% [25]. In a two-step synthesis that included laser ablation of the carbon precursor and further passivation of the resulted CDs with diamine-terminated poly (ethylene glycol), QY was increased up to 10\% [26]. In a one-step synthesis made by laser irradiation of carbon powder suspended in an organic solvent, CDs were obtained with a quantum yield of 5\% [27].

(c) 2020 The Author(s). Published by IOP Publishing Ltd 
Significant progress in CDs preparation has been achieved after an alternative 'bottom-up' approach has been developed several years ago. Particularly, it was demonstrated that organic compounds can generate CDs under thermal decomposition [28-32]. Various organic compounds, such as glucose, citric acid, ascorbic acid (CA), glycine, EDTA have been tested as carbonaceous precursors of CDs as individual components or in the mixture with different additives [33]. In contrast to the top-down approach, bottom-up CDs synthesis allows obtaining highly luminescent CDs (QY > 10\%) in the one-step process, which not requires further activation and stabilization of the particles, can be performed under facile and mild conditions $\left(150{ }^{\circ} \mathrm{C}-300{ }^{\circ} \mathrm{C}\right)$, such as hydrothermal treatment, ultrasonic reaction, microwave-assisted pyrolysis.

From both fundamental and applied perspectives, photoluminescence is one of the most appealing characteristics of CDs. For CDs obtained in bottom-up synthesis, the PL spectra are generally broad and dependent on the excitation wavelength (excitation-dependent photoluminescence). Quantum yield of CDs photoluminescence can vary from 1 to $99 \%$ depending on the precursors and pyrolysis conditions [34]. Due to the unclear mechanism of the bottom-up synthesis, a variation of the experimental conditions such as heating time and temperature cannot provide efficient control of CDs formation and their further aggregation $[1,7,10,30,34]$. Thus, at this point, such an approach has not been able to ensure reproducibility and scalecontrolled yield of the luminescent CDs. Therefore, further procedures are often required to separate CDs from other residues [35]. For instance, size-exclusion chromatography [36], dialysis [37-39] and column chromatography [40] have been used for CDs purification and selection.

Spatial isolation of the CDs precursors before their carbonization can be an alternative approach to the postsynthesis separation of CDs. It can be achieved, for example by adsorption the precursor in the pores of an appropriate host material with further pyrolysis of guest-host composite. In such an approach the pores will serve as quantum confinement nanoreactors and will limit the growth and shape of the CDs.

The synthesis of C-dots in nanoreactors is a very attractive approach. In contrast to conventional chemical reactors, the confined space of nanoreactors can increase the probability of reaction collision and the mass transfer of reactive chemical molecules, thereby greatly improving the efficiency of chemical reactions $[1,10]$. Information about the application of porous nanomaterials as thermal-resistant nanoreactors for the production of CDs is limited. The first proof-of-concept of size-controlling approach was made in [41], where carbon precursor (citric acid) was introduced into the pores of an inorganic framework before pyrolysis. The resulted CDs were received by the dissolution of silica shell in $\mathrm{NaOH}$ with very low QY [41]. Several attempts to use microporous materials in CDs synthesis were published [42-45], but mesoporous materials with pore size larger than $2 \mathrm{~nm}$ are more appropriate for templated synthesis of CDs. The latest results in this subject summarized in table S1 is available online at stacks.iop.org/NANOX/1/010011/mmedia (in the ESM). Among mesoporous materials, silica gels have the most appropriate properties to serve as a nanoreactor for CDs preparation. They have suitable pore size (from 1.5 to $11 \mathrm{~nm}$ ) and hydrophilic surface, about $99 \%$ of the total silica gel surface is the area of mesopores. Thus, templated synthesis of CDs using mesoporous silicas attracts the most attention [46-51].

Nevertheless, information on the application of silica gels as nanoreactors for CDs synthesis if very segmental and insufficient. Particularly, no information available on the effect of the host pore size on the size and luminescent properties of the CDs. Also, the methodology for matrix-assisted CDs preparation, such as precursor loading, optimum duration of synthesis, conditions of CDs removal from the nanoreactor requires further development.

In the current study, four sets of silica gel $\left(\mathrm{SiO}_{2}\right)$ samples having a different diameter of pores (from 4 to $11 \mathrm{~nm}$ ) have been studied as nanoreactors for the preparation of CDs from citric acid. To ensure localization of CA strictly in the template pores, samples of silica gels with adsorbed $\mathrm{CA}\left(\mathrm{SiO}_{2} @ \mathrm{CA}\right)$ were obtained with 60\% of CA maximum loading. Silica gel composites with embedded $\mathrm{CDs}\left(\mathrm{SiO}_{2} @ \mathrm{CDs}\right)$ were prepared at $170{ }^{\circ} \mathrm{C}-200{ }^{\circ} \mathrm{C}$ during 15-600 min Conditions of CDs elution from the host have been also studied. The results were compared with the conventional bottom-up preparation of CDs from CA. Solid $\mathrm{SiO}_{2} @ \mathrm{CD}$ s nanocomposites and water suspension CDs have been characterized by various methods such as SEM, AFM, FTIR, XPS, UV-vis, luminescence spectroscopy (including 3D photoluminescent spectra and excitation-emission map).

\section{Experimental section}

\subsection{Materials}

Citric acid (99.5\%) was purchased from Proquimios (Brazil), sodium hydroxide (99\%) was from Dinamica (Brazil), sodium bicarbonate (99\%) was supplied by Synth (Brazil). Four sets of silica gel (all from SigmaAldrich) were used. Their different porous characteristics, particle size, and geometry are presented in table 1. Calcium hydride (95\%), toluene(99.8\%), and molecular sieves (3 $\AA, 4-8$ mesh) were purchased from SigmaAldrich (USA). Toluene was dried by distillation over calcium hydride and stored in a dark bottle with molecular 
Table 1. Identification and porous characteristics of silica gels used in the current research .

\begin{tabular}{|c|c|c|c|c|}
\hline ID & Sigma-Aldrich ID & Particles type & Particle size $(\mu \mathrm{m})$ & Average pore size $(\mathrm{nm})$ \\
\hline $\mathrm{SiO}_{2}(4)$ & SKU 60735 (SAFC) high-purity grade for column chromatography & irregular & $63-200$ & 4.0 \\
\hline $\mathrm{SiO}_{2}(6)$ & SKU 717185 (Supelco) technical grade & irregular & $40-63$ & 6.0 \\
\hline $\mathrm{SiO}_{2}(9)$ & SKU 60745 (SAFC) high-purity grade for column chromatography & irregular & $63-200$ & 9.0 \\
\hline $\mathrm{SiO}_{2}(11)$ & SKU 80442 (Supelco) $0.7-0.9 \mathrm{~cm}^{3} / \mathrm{g}$ pore volume & spherical & $40-75$ & 11 \\
\hline
\end{tabular}


sieves. All aqueous solutions were prepared with ultra-pure water from a water purification system (The PURELAB Classic, Elga, UK).

\subsection{Characterization}

The textural properties of silica gel samples were determined by means of the low-temperature nitrogen adsorption-desorption method at $77 \mathrm{~K}$ on an ASAP 2020 (Micromeritics, USA). The total pore volume was determined at the maximal adsorption point and specific surface area was calculated through the BET method. The pore size distribution was calculated through the Nguyen-Do approach modified by Gun'ko (MND) [52-55]. The $\mathrm{pH}$ values and the electrical conductivities of supernatant liquids were measured using a PHS-3E meter with a BioTrode lab glass membrane electrode (Hamilton, USA) and HI 8633 conductivity meter (HANNA instruments, UK), respectively. Fourier transform infrared spectroscopy (FT-IR) spectra, recorded within the $4000-400 \mathrm{~cm}^{-1}$ range, were collected on FTLA-2000 spectrophotometer (Thermo Scientific Nicolet). Electronic (UV-vis) absorption spectra (in 200-450 nm range) were measured on a Cary $100 \mathrm{UV}$-vis spectrophotometer (Agilent, USA). X-ray photoelectron spectroscopy (XPS) was used to analyze the surface composition with the help of a $\mathrm{K}_{\alpha} \mathrm{X}$-ray photoelectron spectrometer (Thermo Fisher Scientific, UK) equipped with a high-performance hemispherical electron analyzer with a 128-channel detector and an aluminum anode $\mathrm{X}$-ray source $\left(\mathrm{K}_{\alpha}=1486.6 \mathrm{eV}\right)$, providing an energy resolution of about $1 \mathrm{eV}$. Photoluminescence measurements were realized using LS 55 luminescence spectrometer (Perkin-Elmer, UK) with $1 \mathrm{~cm}$ optical path length quartz cuvettes and with a solid substrate measurement accessory.

The 3D photoluminescence emission spectra were recorded at room temperature and in ultra-high vacuum $\left(10^{-7} \mathrm{mTorr}\right)$ conditions at the Toroidal Grating Monochromator (TGM) beamline of the Brazilian Synchrotron Light Laboratory (LNLS). Photons within the energy range of 4.5-8 eV (276-155 nm) were used as a source of exciting light after filtering on a quartz window. Light emission was transferred by an optical fiber line (aperture: $600 \mu \mathrm{m}$ ) and measured on an R928 Hamamatsu photomultiplier (PMT). The spectra were corrected for the variation in the incident flux of the excitation beam using the excitation and emission spectra of sodium salicylate as standard.

The morphology of the samples was studied by means of a low-vacuum JSM-6490LV (JEOL, Japan) scanning electron microscope (SEM). Atomic force microscopy (AFM) images were obtained using a Bruker MultiMode 8 microscope. A Si tip with a force constant of $0.4 \mathrm{~N} \mathrm{~m}^{-1}$ and a resonance frequency of $70 \mathrm{kHz}$ were used in tapping the peak force method. The samples were diluted in deionized water, ultrasonicated and a single drop was dried on a clean mica surface in a nitrogen flux for $2 \mathrm{~h}$. Statistical analysis of the thickness distribution was performed using Gwyddion 2.53 software.

The powder X-ray diffraction (XRD) pattern of the CDs product was collected at room temperature using a X'Pert PRO (Panalytical, UK) diffractometer equipped with a PIXcel one-dimensional hybrid pixel technology position-sensitive device detector and operated with $\mathrm{Ni}$-filtered $\mathrm{CuK}_{\alpha}$ radiation $(\lambda=1.54178 \AA)$.

Quantum Yield (QY) of CDs was determined from single-point methods [56]. Quinine sulfate in $0.1 \mathrm{M}$ $\mathrm{H}_{2} \mathrm{SO}_{4}$ has been used as a standard. Before the measurements, CDs suspensions and quinine sulfate were diluted to the absorption level below 0.1 at the excitation wavelength $(344-360 \mathrm{~nm})$ in order to minimize reabsorption effects. Both absorbance and photoluminescence emission spectra were measured for these samples. QY of CDs was measured for two excitation light, at 340 and $350 \mathrm{~nm}$ and calculated using equation (1).

$$
Q_{s}=Q_{R} \frac{I_{S}}{I_{R}} \cdot \frac{A_{R}}{A_{S}} \cdot \frac{\eta_{S}^{2}}{\eta_{R}^{2}},
$$

where $Q_{s}=$ quantum yield of CDs; $Q_{R}=$ quantum yield of reference; $I_{S}=$ integrated fluorescence intensity of CDs; $I_{R}=$ integrated fluorescence intensity of reference; $A_{S}=$ absorbance of CDs at $350 \mathrm{~nm}(340 \mathrm{~nm})$; $A_{R}=$ absorbance of reference at $350 \mathrm{~nm}(340 \mathrm{~nm}) ; \eta_{S}=$ refractive index of the solvent of CDs; $\eta_{R}=$ refractive index of the solvent of reference.

The integrated intensity of PL was determined using software SpectraGryph 1.2. The refractive index of water is 1.33 .

\subsection{Conventional bottom-up synthesis of CDs}

Conventional synthesis of CDs was performed by the pyrolysis of bulk citric acid in the inert atmosphere [57]. Briefly, $10 \mathrm{~g}$ of CA was placed into $250 \mathrm{ml}$ two-neck round-bottomed flask and heated to $170{ }^{\circ} \mathrm{C}$ under nitrogen atmosphere using graphite bath. The transparent liquid became orange after $30 \mathrm{~min}$ of heating, which implied the formation of CDs [57]. The resulted liquid was poured out into $130 \mathrm{ml}$ of NaOH $\left(10 \mathrm{mg} \mathrm{ml}^{-1}\right)$ solution under vigorous stirring. The obtained mixture was filtered through a $0.45 \mu \mathrm{m}$ filter to remove large particles and stored for further analysis in the refrigerator $\left(\right.$ at $\left.4{ }^{\circ} \mathrm{C}\right)$. 


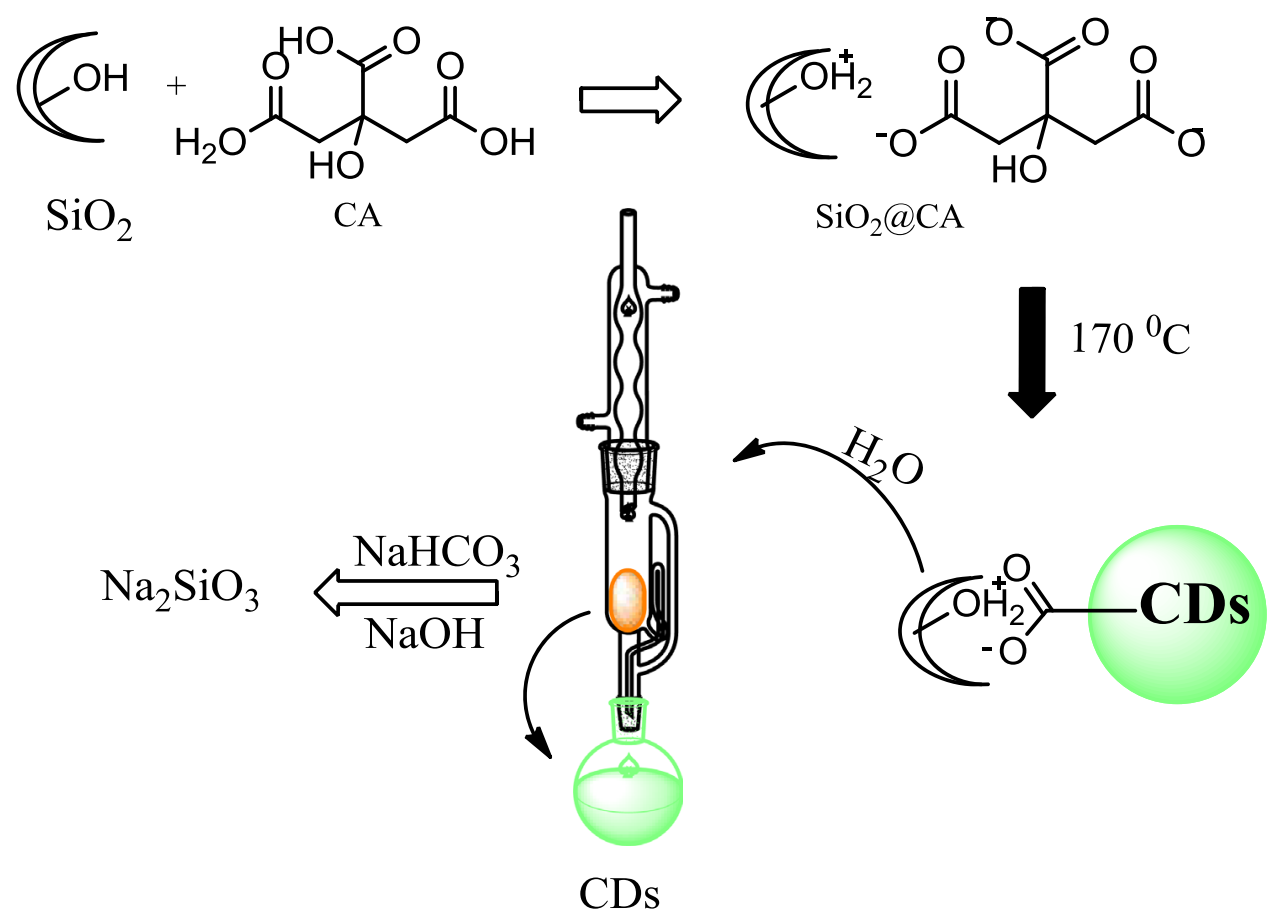

Figure 1.Scheme of $\mathrm{SiO}_{2} @ \mathrm{CA}$ preparation, thermal treatment, and elution of CDs.

\subsection{Preparation of $\mathrm{SiO}_{2} @ \mathrm{CA}$ composite}

General scheme of $\mathrm{SiO}_{2} @ \mathrm{CA}$ preparation, thermal treatment, and CDs elution is presented in figure 1.

A set of silica-based composites having CA adsorbed was prepared from bulk silica SiO $\mathrm{O}_{2} \mathrm{CA}$. The set consists of four silica samples with different porosity and was prepared using a similar procedure by adding $1.0 \mathrm{ml}$ of CA aqueous solution $\left(1.5 \mathrm{~g} \mathrm{ml}^{-1}\right)$ to $1.0 \mathrm{~g}$ of silica. The mixture was sonicated for $10 \mathrm{~min}$ and the excess of liquid was removed by blotting it with filter paper until dry. Then $2 \mathrm{~mL}$ of diethyl ether was added to silica composite and shaken for $20 \mathrm{~min}$ Excess of ether was removed by decantation and the procedure was repeated twice. Finally, the samples were dried under vacuum $(0.1$ Torr $)$ at $60^{\circ} \mathrm{C}$ producing a loose powder.

An additional sample of $\mathrm{SiO}_{2} @ \mathrm{CA}$ was prepared as a reference $\left(\mathrm{rSiO}_{2} @ \mathrm{CA}\right)$ by following the experimental procedure, recommended in [41]. Briefly, $200 \mathrm{mg}$ of silica gel $\mathrm{SiO}_{2}(11)$ and $100 \mathrm{mg}$ of CA were mixed and sonicated in $0.5 \mathrm{ml}$ of water. The mixture was dried (without filtration and washing) in an oven at $60{ }^{\circ} \mathrm{C}$, producing an agglutinated powder.

\subsection{Thermal treatment of $\mathrm{SiO}_{2} @ \mathrm{CA}$}

All silica gels samples were heated at $170{ }^{\circ} \mathrm{C}$ and $200{ }^{\circ} \mathrm{C}$ under nitrogen atmosphere. Portions of the samples were collected at different treatment time $(\tau)$, from 15 to 720 min, to obtain $\mathrm{SiO}_{2} @ \mathrm{CDs}-\tau$.

\subsection{Releasing $\mathrm{CDs}$ from $\mathrm{SiO}_{2} @ \mathrm{CDs}$}

The conditions of CDs releasing from $\mathrm{SiO}_{2} @ \mathrm{CD}$ s were studied in three consecutive steps: (1) the composites were suspended in $5 \mathrm{ml}$ of water and shaken for $15 \mathrm{~min}$. The solid phase was separated by filtration and the washing procedure was repeated till no fluorescence was observed for the filtrate. Alternatively, $\mathrm{SiO}_{2} @ \mathrm{CD}_{\text {s were }}$ washed in Soxhlet apparatus with water. The supernatant was collected, filtrated through a $0.22 \mu \mathrm{m}$ filter and stored at $0{ }^{\circ} \mathrm{C}$. (2) The samples were washed with $0.1 \mathrm{~mol} \mathrm{l}^{-1} \mathrm{NaHCO}_{3}$ solution (portions of $5 \mathrm{ml}$ ) in the same manner as it is described for the first step. The supernatant was collected and stored equally. (3) Finally, the silica scaffold was dissolved in $3 \mathrm{ml}$ of $\mathrm{NaOH}$ solution $\left(3 \mathrm{~mol} \mathrm{l}^{-1}\right)$ at room temperature.

\section{Results and discussion}

\subsection{Morphological properties of host silicas}

For proper preparation of CDs under the nanoreactor approach, it is critical to use the hosts with suitable pore size. It is generally accepted that CDs have a particle size of less than $10 \mathrm{~nm}[5,7,58]$. Therefore, in contrast to earlier publications where microporous zeolites with small particle size have been used, silica gels with 4-11 nm nominal pore diameter and large particles $(40-200 \mu \mathrm{m})$ is used in the current research, table 1 . The latter shall 


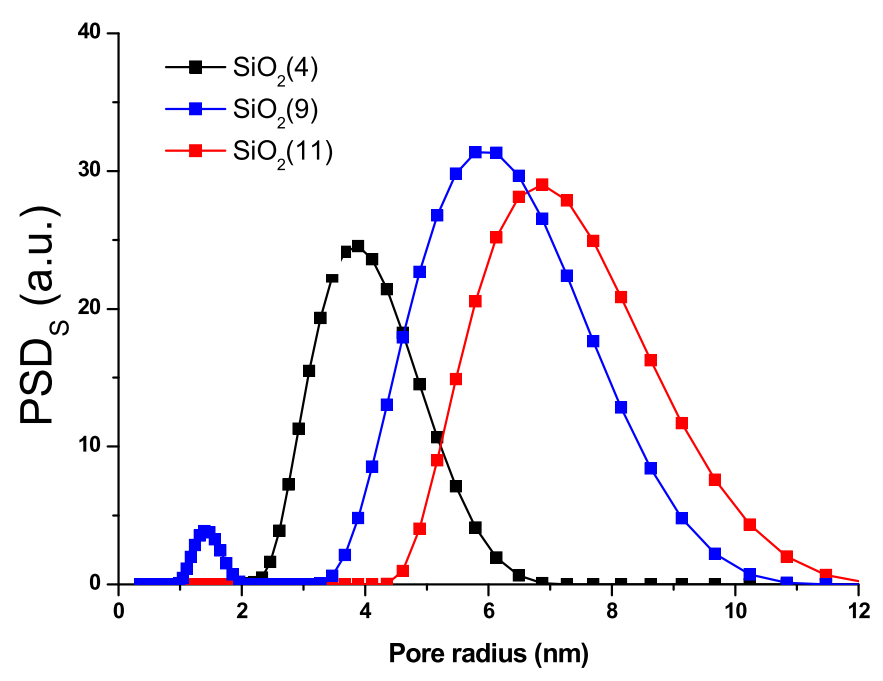

Figure 2. The incremental pore size distribution by surface area of silica gels used for $\mathrm{SiO}_{2} @ \mathrm{CD}$ s preparation.

Table 2. Porous characteristics of silica gel hosts.

\begin{tabular}{|c|c|c|c|c|c|}
\hline Silica denoted & $\begin{array}{l}\text { Maximum Loading of CA on } \\
\qquad \mathrm{SiO}_{2}\left(\mathrm{gg}^{-1}\right)\end{array}$ & $\begin{array}{l}\text { Average pore } \\
\text { size }(\mathrm{nm})\end{array}$ & $\begin{array}{l}\text { Pore volume } \\
\left(\mathrm{cm}^{3} \mathrm{~g}^{-1}\right)\end{array}$ & $\begin{array}{c}\mathrm{S}_{\mathrm{BET}} \\
\left(\mathrm{m}^{2} \mathrm{~g}^{-1}\right)\end{array}$ & $\begin{array}{c}\mathrm{S}_{\text {meso }} / \mathrm{S}_{\mathrm{BET}}, \\
\operatorname{MND}(\%)\end{array}$ \\
\hline $\mathrm{SiO}_{2}(4)$ & 1.1 & 5.5 & 0.72 & 360.3 & 94.9 \\
\hline $\mathrm{SiO}_{2}(6)$ & 1.2 & $6.0^{\mathrm{a}}$ & 0.80 & - & - \\
\hline $\mathrm{SiO}_{2}(9)$ & 1.5 & 6.9 & 1.01 & 387.4 & 99.8 \\
\hline $\mathrm{SiO}_{2}(11)$ & 1.9 & 10.2 & 1.25 & 400.2 & 99.6 \\
\hline
\end{tabular}

a data from the manufacturer.

reduce CA adsorption on an external area of the particles and so prevent the formation of CDs outside of the pores.

Since porous characteristics of the host are essential for the nanoreactor approach, they were justified form nitrogen adsorption experiment. It was confirmed that the selected silica samples have the desirable pore sizes from 5.5 to $10.2 \mathrm{~nm}$, with $0.7-1.25 \mathrm{~cm}^{3} \mathrm{~g}^{-1}$ pore volume, table 2 . Accordingly, the mesopores contribute more than $95 \%$ (commonly $99.7 \pm 0.3$ ) to the overall porosity of the silica gels, table 2 . Selected samples of the host have a unimodal and narrow distribution of the pores (figure 2), which allows expecting the narrow distribution of hosted CDs particles.

\subsection{Preparation of $\mathrm{SiO}_{2} @ \mathrm{CA}$}

A crucial aspect of the nanoreactor synthesis of CDs is verification that a major part of the precursor is localized in the host pores. To ensure this, the volume of CA solution used for the preparation of $\mathrm{SiO}_{2} @ \mathrm{CA}$ composites was limited by pore volumes of the silica gels. Also, high loading of hydrophilic silanol groups on the silica surface ensures good affinity of CA to the host. Taking into account the pore volume of silica gel samples and solubility of CA in water $\left(1.5 \mathrm{~g} \mathrm{ml}^{-1}\right)$ maximum loading of the precursor was estimated, table 2 . For example, $1 \mathrm{~g}$ of silica $\mathrm{SiO}_{2}(11)$ can hold up to $1.9 \mathrm{~g}$ of CA inside of the pores. Nevertheless, after the treatment of silica gel even with a small volume of liquid, wet material is always obtained due adsorption of some part of the water solution on inter-particle space. In order to obtain $\mathrm{SiO}_{2} @ \mathrm{CA}$ having the precursor in the pores only, this interparticle liquid having dissolved compounds must be removed before the pyrolysis. To prove the importance of such pretreatments, a sample labeled as $\mathrm{rSiO}_{2}(11) @ \mathrm{CA}$ was prepared according to the procedures recommended in $[41,42,59]$. By comparison of mass the silica sample before and after treatment with CA, it was found that loading of $\mathrm{CA}$ on $\mathrm{rSiO}_{2}(11) @ \mathrm{CA}$ constitute of $112 \%$ of maximum pore capacities for this material. Therefore, after drying $\mathrm{rSiO}_{2}(11) @ \mathrm{CA}$ is a compact glued agglomerate. After two consecutive rinsings of $\mathrm{rSiO}_{2}(11) @ \mathrm{CA}$ with ether, CA loading is reduced to $60 \%$ of maximum pore capacity. Such samples of $\mathrm{SiO}_{2} @ \mathrm{CA}$ present itself as a loose dry powder. The SEM images confirm the difference between $\mathrm{rSiO}_{2} @ \mathrm{CA}$ particles and $\mathrm{SiO}_{2}(11) @ \mathrm{CA}$ particles (figure 3), demonstrating a lot of CA microcrystals located on the external surface of $\mathrm{rSiO}_{2} @ \mathrm{CA}$ and absence of those on $\mathrm{SiO}_{2}(11) @ \mathrm{CA}$. 

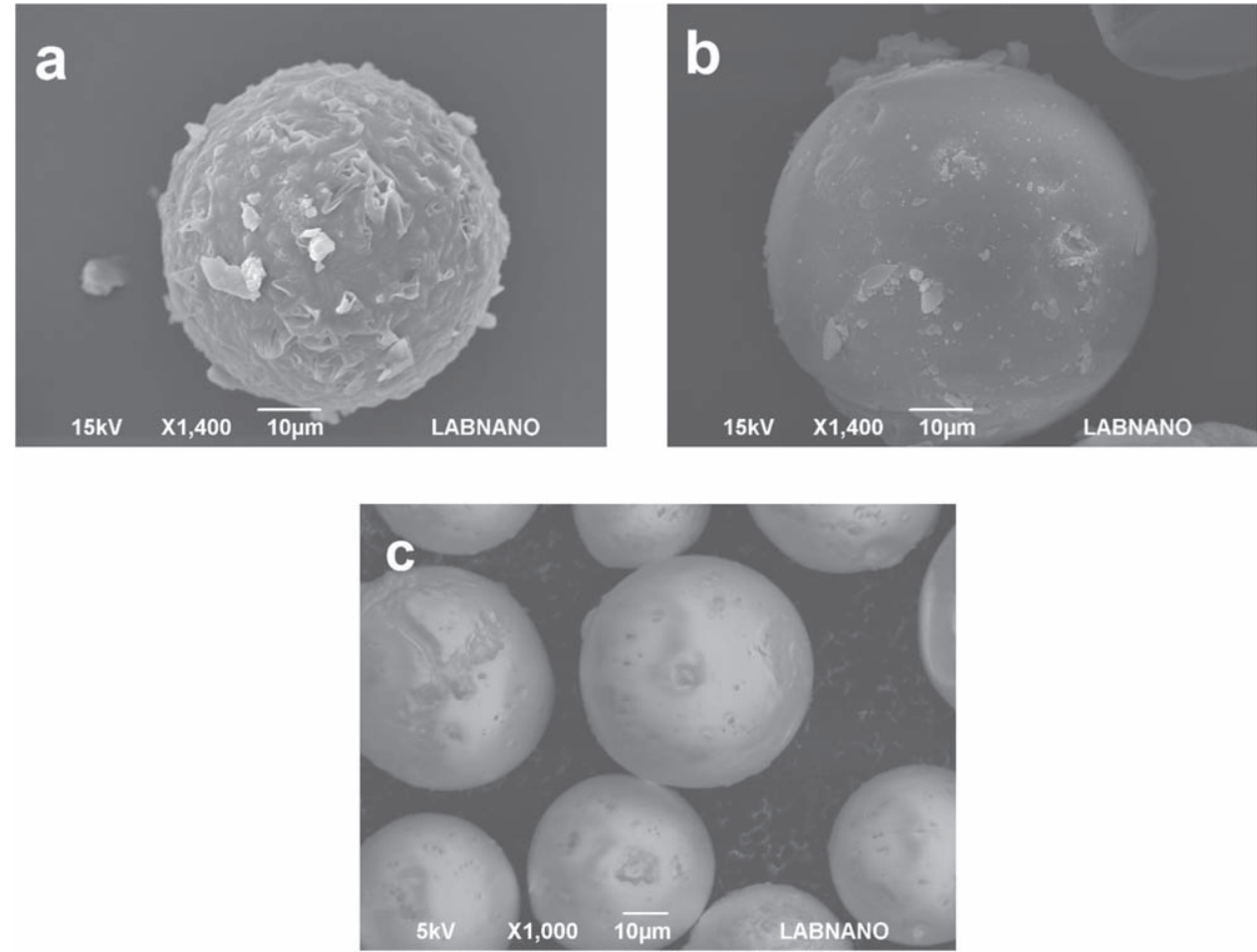

Figure 3. SEM images of $\mathrm{rSiO}_{2} @ \mathrm{CA}(\mathrm{a}), \mathrm{SiO}_{2}(11) @ \mathrm{CA}(\mathrm{b})$, and pristine $\mathrm{SiO}_{2}(11)$ (c).

Table 3. Overview of the host samples used for the preparation of CDs from citric acid precursor.

\begin{tabular}{lccr}
\hline Host & Pore diameter, nm & Time of pyrolysis, min & Post-treatment \\
\hline $\mathrm{SiO}_{2}$ & $5.5,6.0,6.9,10.2$ & $5,15,30,60,120,240,360,600$ & $\mathrm{H}_{2} \mathrm{O}, \mathrm{NaHCO}_{3}, \mathrm{NaOH}$ \\
- & n.a. & 180 & $\mathrm{H}_{2} \mathrm{O}, \mathrm{NaHCO}_{3}$ \\
\hline
\end{tabular}

Thus, the importance of the procedure for removing CA excess from an outer surface of silica composite was considered. In order to do so, wet samples of as-prepared $\mathrm{SiO}_{2} @ \mathrm{CA}$ were blotted with filter paper until dry and then were washed out with two portions of diethyl ether. The ether is not miscible with water, therefore it was expected that ether will not penetrate the pores of wet $\mathrm{SiO}_{2} @ \mathrm{CA}$ filled by water and so will remove the excess of CA form the external surface of the particles only. It could get samples of $\mathrm{SiO}_{2} @ \mathrm{CA}$ with high loading of CA in the poses and clean outer surface as it is demonstrated in figure 3.

\subsection{Preparation and characterization of $\mathrm{SiO}_{2} @ \mathrm{CDs}$ composites}

\subsubsection{Synthesis of $\mathrm{SiO}_{2} @ \mathrm{CDs}$}

Four samples of silica-based material were used as a host for CDs precursors. After impregnation with the precursor and pre-treatment, samples of $\mathrm{SiO}_{2} @ \mathrm{CA}$ were thermally treated in an inert atmosphere at $170{ }^{\circ} \mathrm{C}$ for 5-600 min and then subsequently washed with water, $\mathrm{NaHCO}_{3}$, and $\mathrm{NaOH}$ to release CDs, table 3 .

Earlier it was shown that appropriate temperature for conventional CDs synthesis from $\mathrm{CA}$ is $150{ }^{\circ} \mathrm{C}-200^{\circ} \mathrm{C}$ $[34,60]$. The temperature in $170^{\circ} \mathrm{C}$ was chosen as the middle of the optimal interval and maintained constant in order to compare the results of pyrolysis for different samples. Conventional CDs were also obtained by pyrolysis of CA at $170{ }^{\circ} \mathrm{C}$ for 180 min After the thermal treatment $\mathrm{SiO}_{2} @ \mathrm{CDs}$ had light brown, and conventional CDs black color ${ }^{1}$, figures S1-S2 in the ESM. Under UV light, $\mathrm{SiO}_{2} @ \mathrm{CDs}$ demonstrated bright blue photoluminescence, figure 4. The reference sample $\mathrm{rSiO}_{2} @ \mathrm{CDs}$ has a brown color with randomly-distributed photoluminescence, figure S2 in the ESM.

\subsubsection{FT-IR spectra}

The FTIR spectrum of silica gel host exhibits several peaks related to silanol groups: at $3750 \mathrm{~cm}^{-1}$ for isolated Si-OH; 3670-3220 $\mathrm{cm}^{-1}$ for hydrogen-bonding Si-OH; at $1640 \mathrm{~cm}^{-1}$ deformation vibration Si-OH. Also, FTIR spectra of silica host demonstrate two peaks at $1800-2000 \mathrm{~cm}^{-1}$ that corresponds to overtones from $\mathrm{Si}-\mathrm{O}-\mathrm{Si}$

${ }^{1}$ After 30 min of thermal treatment of $\mathrm{CA}$ at $170{ }^{\circ} \mathrm{C}$ it melts to yellow colour liquid, figure $\mathrm{S} 1$ in the ESM. 

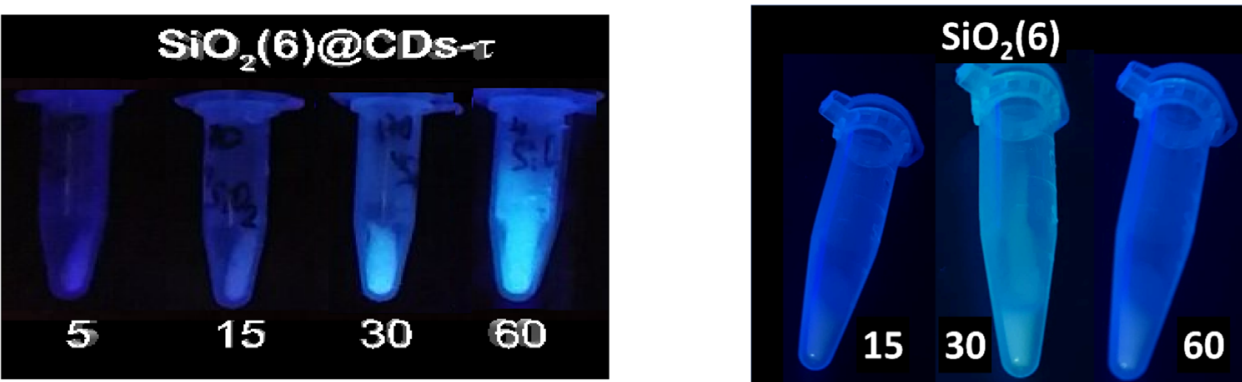

Figure 4. Images of of $\mathrm{SiO}_{2}(6) @ \mathrm{CDs}$ and $\mathrm{SiO}_{2}(6)$ treated for different time (5-60 min) at $170{ }^{\circ} \mathrm{C}$, under illumination with $365 \mathrm{~nm}$ light.

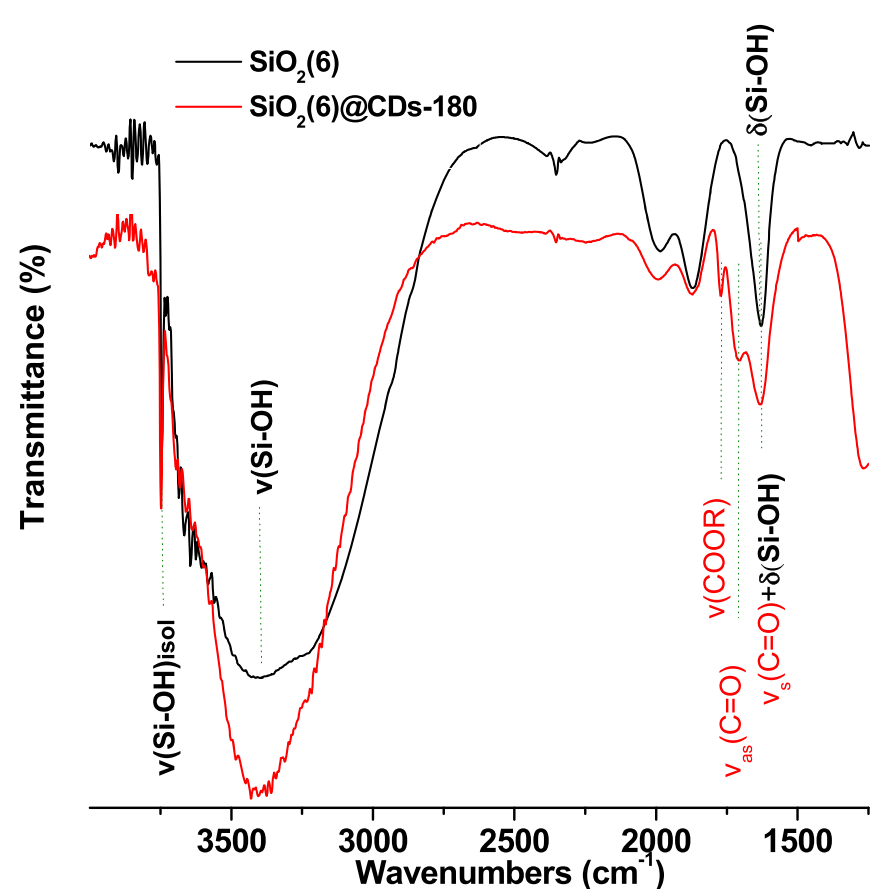

Figure 5. FTIR spectra of $\mathrm{SiO}_{2}(6) @ \mathrm{CDs}-180$ and pristine $\mathrm{SiO}_{2}$.

stretching vibrations, figure 5. Spectrum of $\mathrm{SiO}_{2}(6) @ \mathrm{CDs}-180$ reveal itself as a superposition of the host and the guest (CDs) and in addition to the bands of silica, $\mathrm{SiO}_{2}(6) @ \mathrm{CDs}-180$ sample demonstrates well-defined peaks at $1775 \mathrm{~cm}^{-1}$ and $1702 \mathrm{~cm}^{-1}$ that can be attributed to stretching vibration of $\mathrm{C}=\mathrm{O}$ fragments in $-\mathrm{C}(\mathrm{O})(\mathrm{OR})$ and -COOH functional groups of silica-adsorbed CDs [51,59].

\subsubsection{XPS spectra}

The XPS survey spectra for the $\mathrm{SiO}_{2}$ (6)@CDs-180 (figure 6(a)) indicate predominantly O1s, C1s, Si2s and Si2p peaks centered, respectively, at 532, 286, 155 and $103 \mathrm{eV}$.

The high-resolution C1s XPS spectra of samples revealed different types of carbon atoms in CDs. Curvefitting analysis of high-resolution XPS of C1s reveals bands at $284.5 \mathrm{eV}, 286.3,287.5$ and $289 \mathrm{eV}$ that can be assigned to C-C (44\%), C-OH (24\%), carbonyl (26\%) and carboxyl (6\%) groups, correspondingly [24], figure 6(c). This king of XPS is very typical for CDs and demonstrates the formation of partly decarboxylated CDs. A weak band at 551,5 eV attributed to carbonyl fragments in CDs can be seen in high-resolution O1s XPS spectrum of $\mathrm{SiO}_{2}$ (6)@CDs-180, figure 6(b). This kind of group is common for CDs obtained earlier [1].

\subsubsection{Photoluminescence of solid composites $\mathrm{SiO}_{2} @ C D s-\tau$.}

The incipience of CDs has been monitored by measuring the photoluminescence from solid samples of $\mathrm{SiO}_{2} @ \mathrm{CDs}$ obtained for different time of thermal treatment, figure 7. Evidently, the CDs are formed in silica pores very quickly. At least, luminescence of $\mathrm{SiO}_{2} @ \mathrm{CDs}$ can already be detected after 5 min of $\mathrm{SiO}_{2} @ \mathrm{CA}$ treatment at $170^{\circ} \mathrm{C}$. However, the position of PL maximum $(420 \mathrm{~nm})$ for $\mathrm{SiO}_{2} @ \mathrm{CD}$ obtained after such a short 


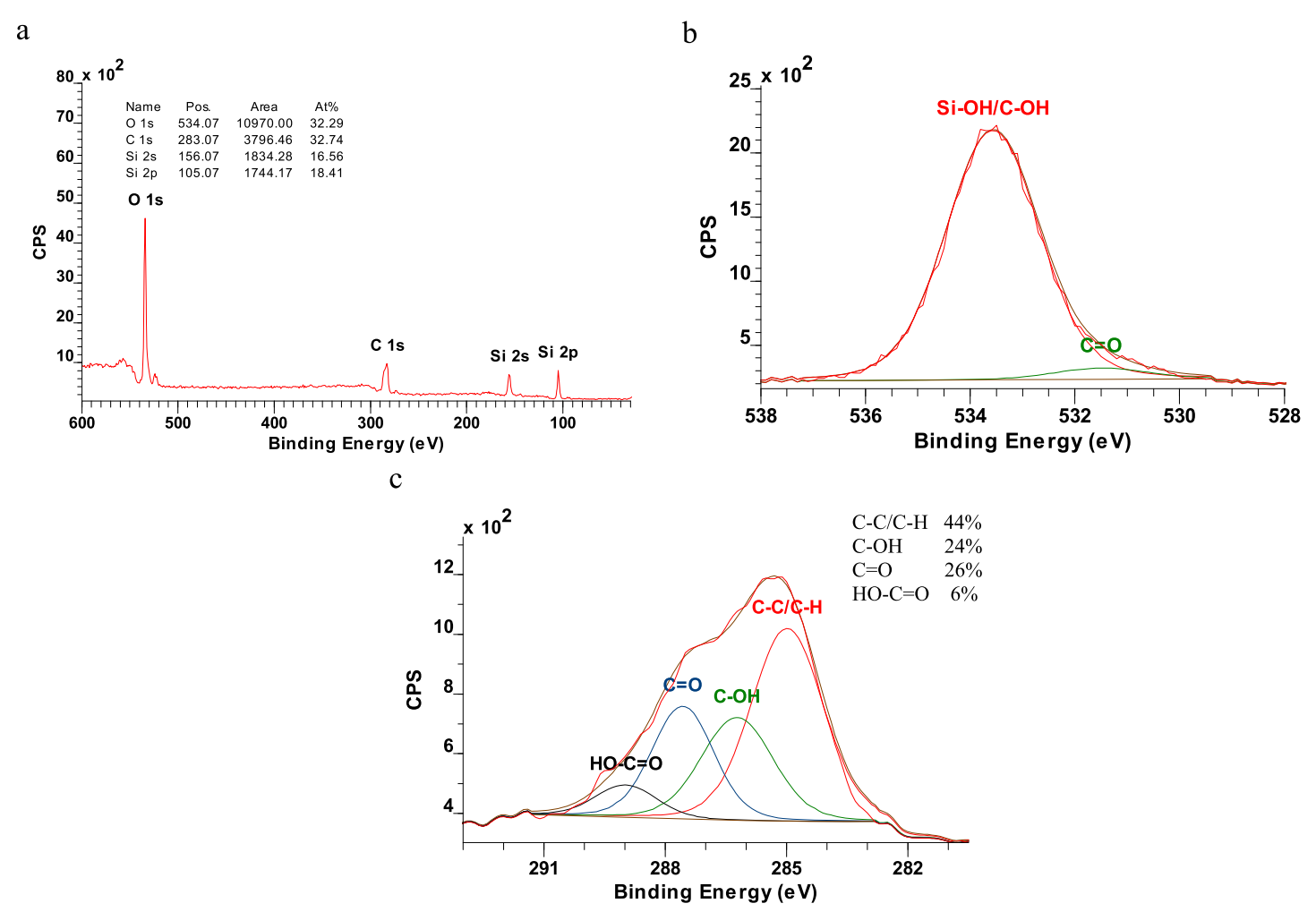

Figure 6. Survey (a) and high resolution fitted XPS spectra (b, c) of $\mathrm{SiO}_{2}(6) @ \mathrm{CDs}-180$ in O1s (b) and C1s (c) regions.

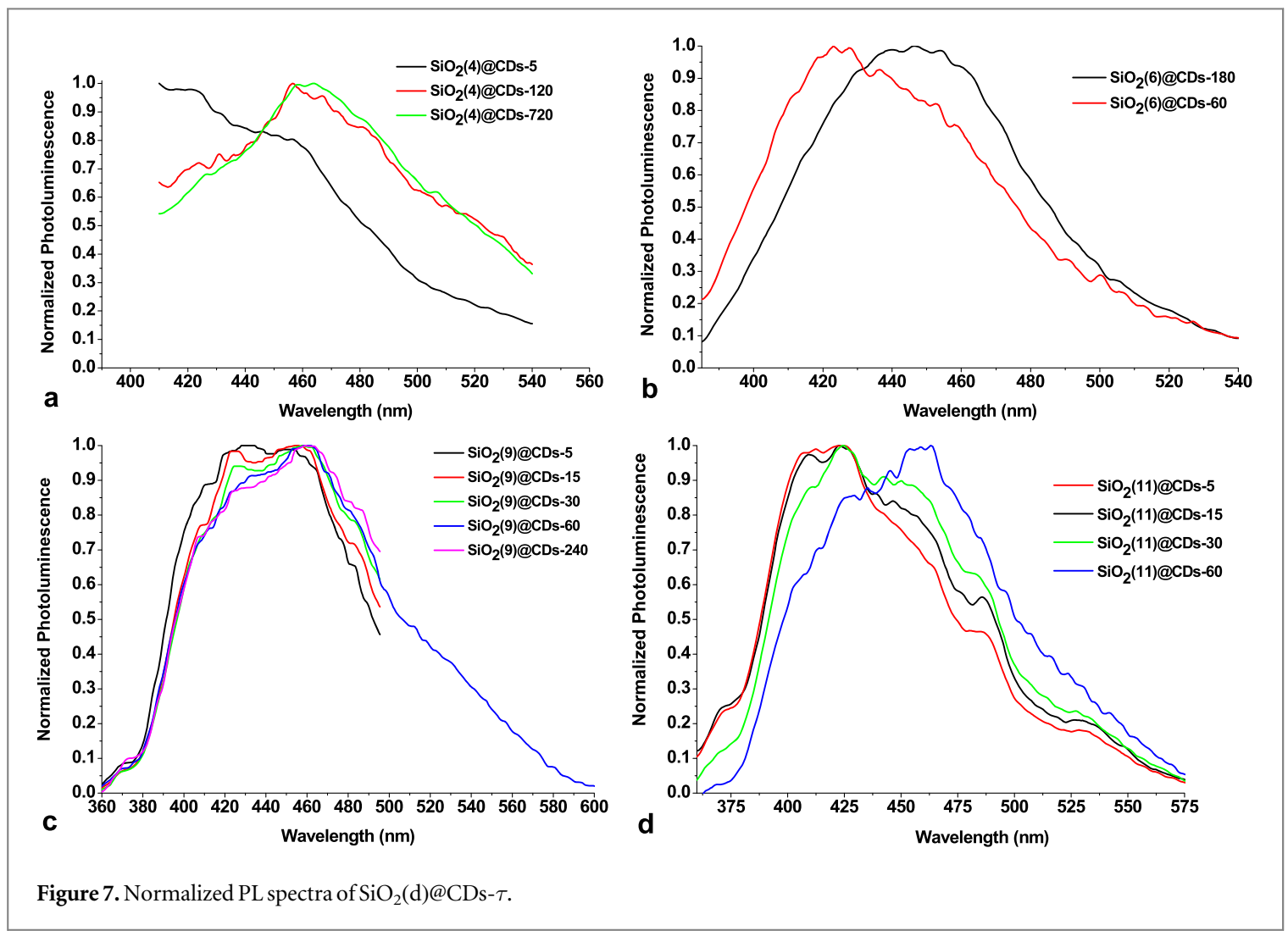



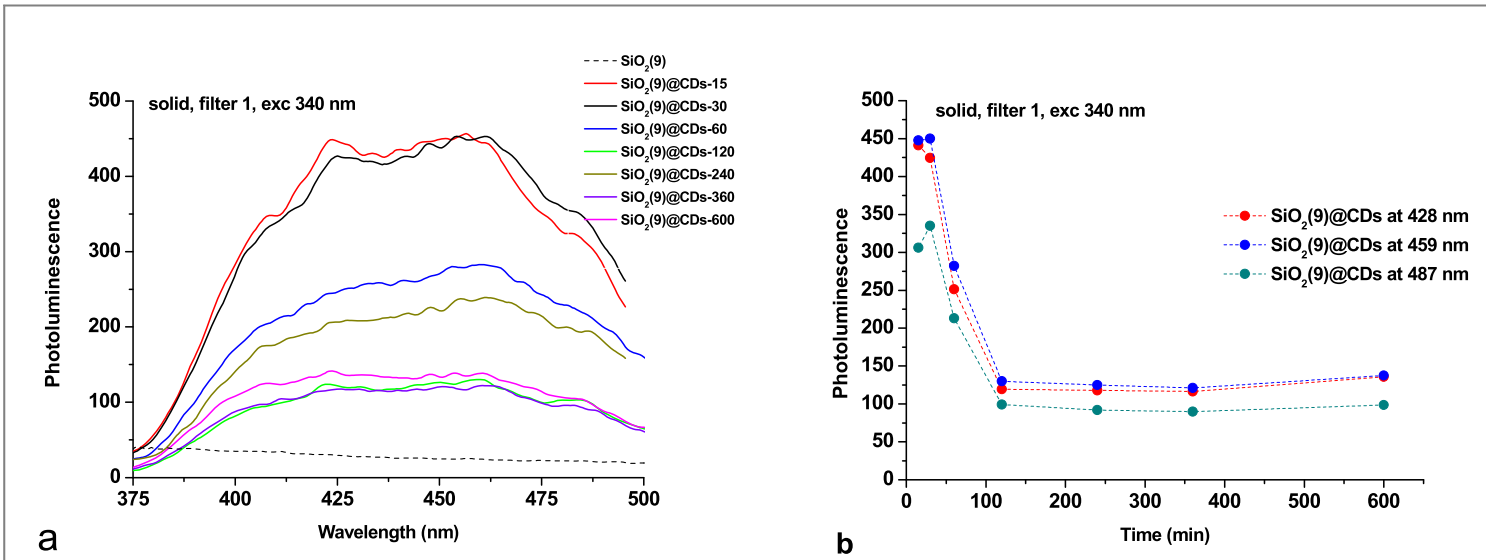

Figure 8. Photoluminescence spectra of $\mathrm{SiO}_{2}(9) @ \mathrm{CDs}-\tau$ for different time of the thermal treatments (a), and changes of photoluminescent intensity versus time (b).

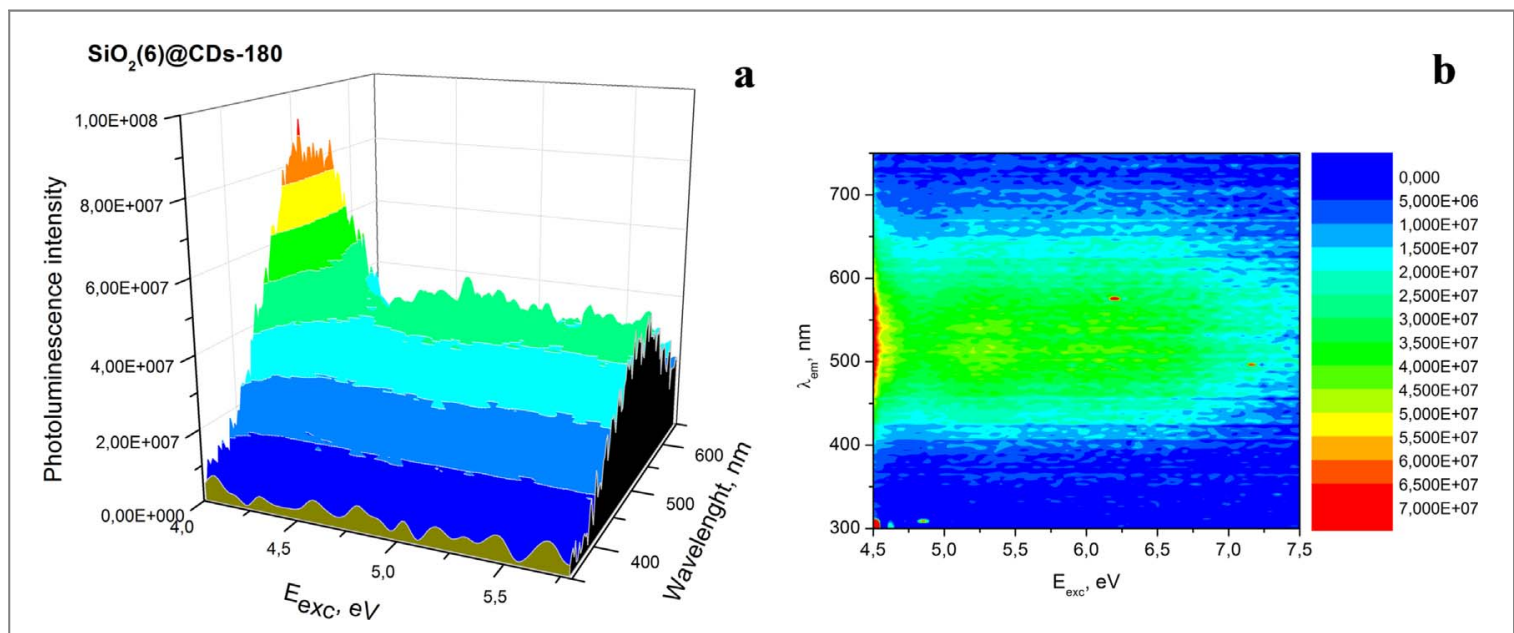

Figure 9.3D photoluminescent spectra and excitation-emission map of $\mathrm{SiO}_{2}(6) @ \mathrm{CDs}-180$ (a), (b).

time (5-60 min) does not match to PL of CDs obtained from CA by conventional methods (445 $\mathrm{nm}$ ) [28]. Together with the peak at $420 \mathrm{~nm}, \mathrm{PL}$ spectra of all SiO ${ }_{2} @ \mathrm{CDs}$ exhibit a peak at $450 \mathrm{~nm}$, figure 7 . Thus, PL spectra of $\mathrm{SiO}_{2} @ \mathrm{CA}$ commonly show a wide band, which consists of two peaks at 420 and $450 \mathrm{~nm}$.

While the peak positions do not substantially depend on the time of $\mathrm{SiO}_{2} @ \mathrm{CD}$ s thermal treatment and the size of the host pores, the relative intensity of long-wave emission rises with time for all studied $\mathrm{SiO}_{2} @ \mathrm{CDs}$ that can manifest the development of CDs with enhanced decarboxylation degree.

The absolute intensity of $\mathrm{SiO}_{2} @ \mathrm{CDs}$ reaches its maximum for 15-30 min of $\mathrm{SiO}_{2} @ \mathrm{CA}$ thermal treatment and then sharply declines for all studied samples, figure 8(a). After $100 \mathrm{~min}$ of the treatment, no further depression of PL was observed, figure 8(b).

The photoluminescence spectra of $\mathrm{SiO}_{2} @ \mathrm{CD}$ s clearly exhibit the formation of CDs captured in silica pores. Apparently, those CDs also have different sizes and shapes since they are characterized by multiple maxima in PL spectra of $\mathrm{SiO}_{2} @ \mathrm{CD}$. The nature of the PL band at $420 \mathrm{~nm}$ calls for further investigations.

The $\mathrm{SiO}_{2} @ \mathrm{CD}$ composites also demonstrate photoluminescence that occurs under excitation with high energy radiation (165-276 nm, 7.5-4.5 eV). For example, $\mathrm{SiO}_{2}(6) @ \mathrm{CDs}$ generates wide emission with a maximum at $525 \mathrm{~nm}$, figure 9(b). From two-dimensional mapping, as a function of the excitation energy, it can be seen that the peak position of photoluminescence emission almost does not change in the function of excitation energy, figure 9(a). The most intense photoluminescence for $\mathrm{SiO}_{2}$ (6)@CDs is observed at 4.0-4.2 eV (310-295 nm). Presumably, $\mathrm{SiO}_{2}(6) @ \mathrm{CDs}$ can be useful for adsorption and transformation of short wave UV radiation.

\subsection{Elution of CDs from the host}

To elute the resulted CDs from the silica host three consecutive steps were applied. First, they were thoroughly washed with water until the conductivity of the washing solution droped down essentially and absorption at 300 nm was about zero, figures $10(\mathrm{a})$, (b). 


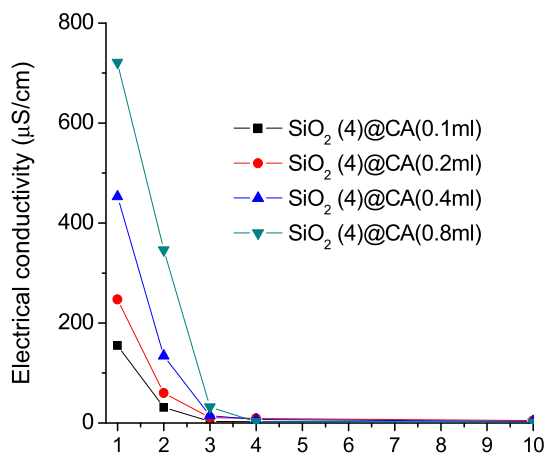

a The number of cycles of adding/decanting water

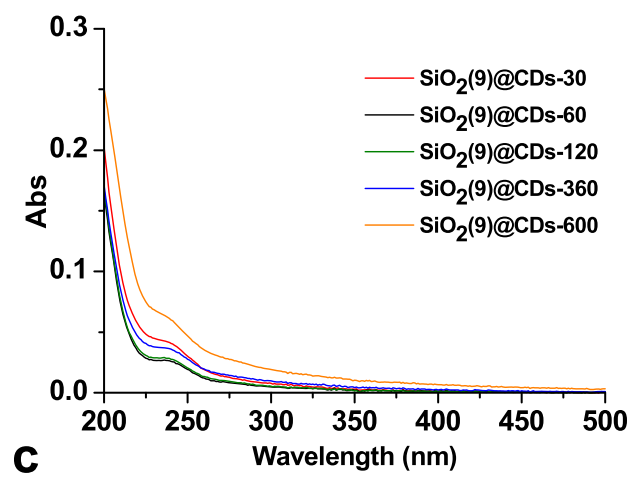

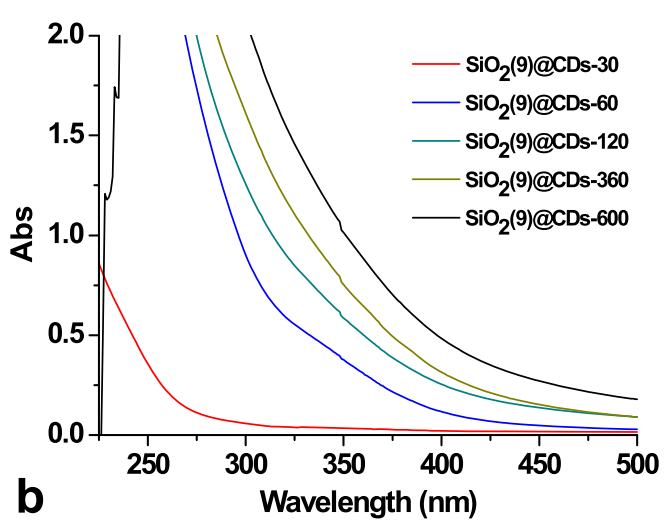

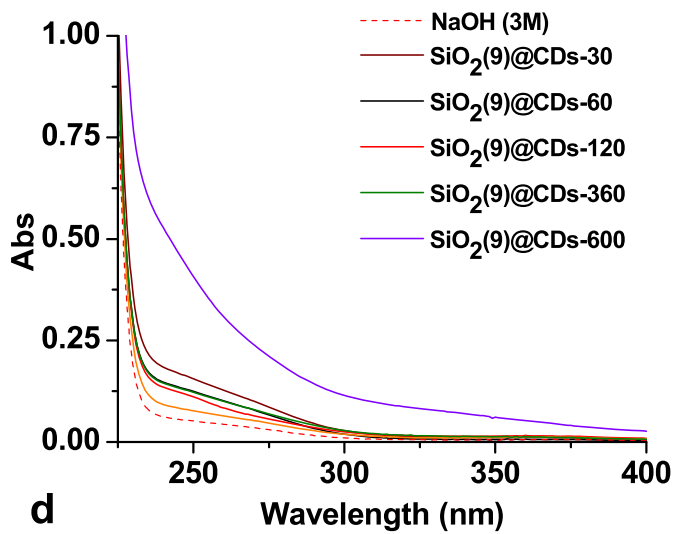

Figure 10. (a) Electroconductivity of supernatant solution obtained after immersing of $\mathrm{SiO}_{2}(4) @ \mathrm{CDs}-60$ ( $\left.0.5 \mathrm{~g}\right)$ to $10 \mathrm{ml}$ of water with further filtration and cycling the procedure; (b)-(d) UV-vis spectra of the supernatant solutions, obtained by successive treatment of $\mathrm{SiO}_{2}$ (4)@CDs-60 with water (b), $0.1 \mathrm{~mol} \mathrm{l}^{-1} \mathrm{NaHCO}_{3}$ (c), 3 mol $\mathrm{l}^{-1} \mathrm{NaOH}$ (d) after different time of the thermal treatment.

Then, $0.1 \mathrm{~mol}^{-1}$ of $\mathrm{NaHCO}_{3}$ water solution was exploited for the same purposes. Finally, $\mathrm{SiO}_{2} \mathrm{scaffold}$ was dissolved in $\mathrm{NaOH}$. It has been found that water elutes strongly luminescent CDs from all samples of $\mathrm{SiO}_{2} @ \mathrm{CDs}-\tau$. Four washing cycles were enough to remove most of the trapped CDs, figure 10(a). Further washing of $\mathrm{SiO}_{2} @ \mathrm{CDs}-\tau$ with $\mathrm{NaHCO}_{3}$ and even solubilization of the host in $\mathrm{NaOH}$ do not reveal an essential quantity of the CDs, except for the samples treated for $600 \mathrm{~min}$, figures 10(c), (d). The fact of a weak affinity of the CDs to the $\mathrm{SiO}_{2}$ host can be concluded from this experiment. It also can be assumed that silica gel is more appropriate host for confining of CDs particles then earlier used zeolites because it releases the CDs through treatment with water and does not require solubilization of the host in alkali solution.

During the thermal treatment of $\mathrm{SiO}_{2} @ \mathrm{CA}$, most of CDs are growing inside of the host pores without essential interaction with the surface of silica. Such a type of CDs particles can be eluted with water from the hosts. Immersing of $\mathrm{SiO}_{2} @ \mathrm{CDs}$ into $\mathrm{NaHCO}_{3}$ solution promotes ionization of silanol groups of silica surface and carboxylic fragments on CDs surface. Next, negatively charged silica surface stimulates elution of the negatively charged CDs.

\subsection{Characterization of CDs}

\subsubsection{Microscopy}

AFM technique was utilized to probe the sample topography and measure particle height. AFM image of CDs prepared from $\mathrm{rSiO}_{2} @ \mathrm{CDs}$ according to the procedure [41] shows the wide distribution of the particle's height mainly from 5 to $8 \mathrm{~nm}$, figure 11(a). The CDs obtained from $\mathrm{SiO}_{2}(4) @ C D s-180$ have a smaller height (2-4 nm) and narrower distribution profile, figure 11(b).

These data support the results reflected on the SEM images of $\mathrm{rSiO}_{2} @ \mathrm{CA}$ particles (figure 3), suggesting the possible formation of CDs on the outer surface of the silica template. If so, the growth of such particles is not confined by the template, and CA pyrolysis can lead to formation CDs with size, larger than the size of silica pores. On the contrary, the experimental procedure proposed in current research demonstrates a narrow distribution of the CDs particle height. Thus, the importance of the pre-treatment of $\mathrm{SiO}_{2} @ \mathrm{CA}$ nanocomposites for removing CA excess that can be adsorbed on the outer surface of silica is feasible. 

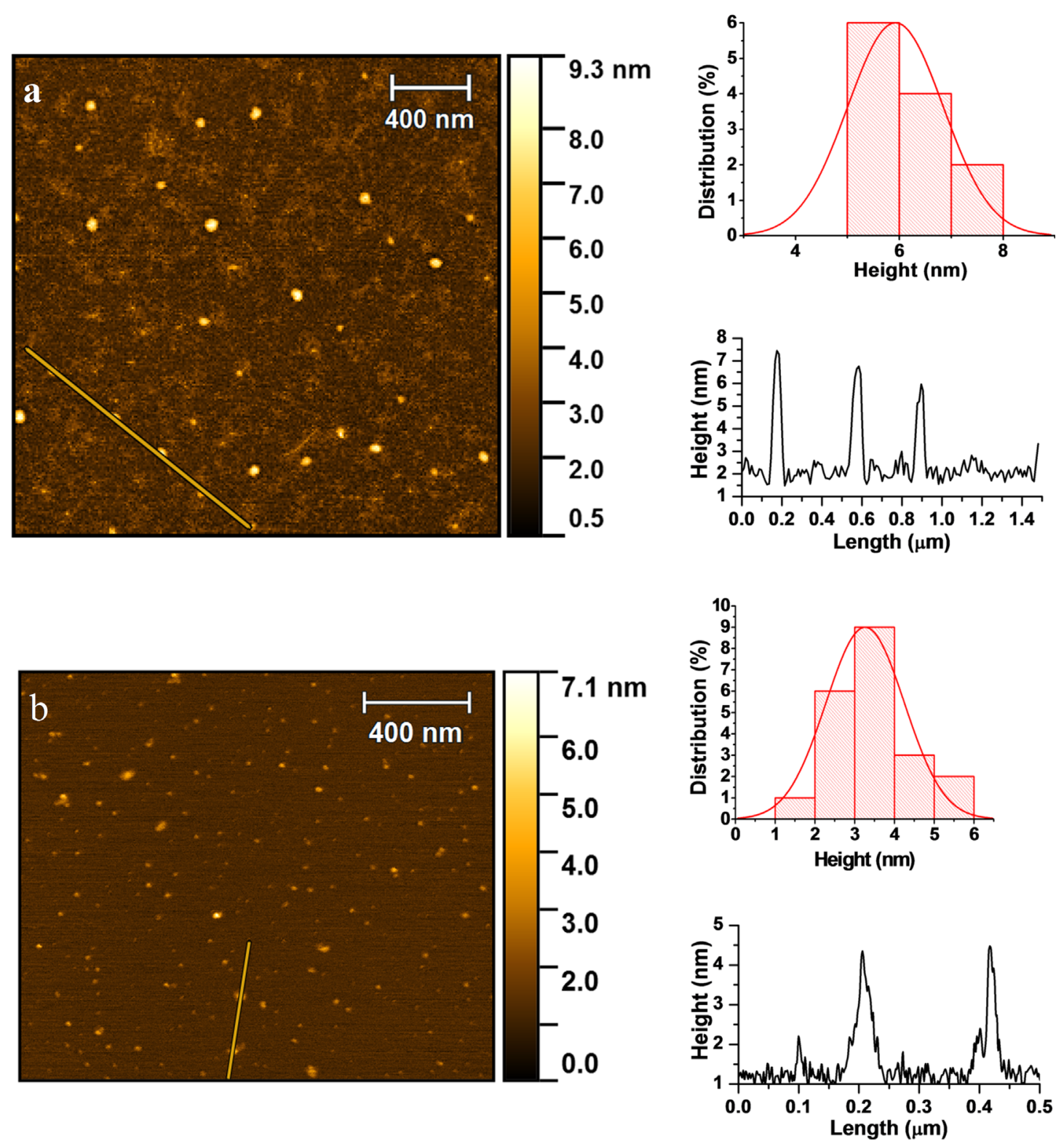

Figure 11. AFM images (left), height distribution (upper right) and profile (lower right) of the CDs obtained from rSiO $\mathrm{C}_{2} @ \mathrm{CDs}$ (a) and $\mathrm{SiO}_{2}(4) @ \mathrm{CDs}-180$ (b) after their elution with water.

3.5.2. The $x$-ray diffraction of CDs.

XRD pattern of CDs washed out from $\mathrm{SiO}_{2}-\mathrm{NH}_{2} @ \mathrm{CDs}-120$ with water shows a broad peak centered at $2 \theta=23.2^{\circ}(0.34 \mathrm{~nm})$, which is commonly attributed to the amorphous highly disordered carbon atoms in CDs [56], figure $\mathrm{S} 3$ in the ESM.

\subsubsection{Photoluminescence of CDs obtained in nanoreactors}

All CDs eluted from $\mathrm{SiO}_{2}$ hosts exhibit emission band centered at $447 \mathrm{~nm}$, figure 12 . The band intensity essentially depends on the time of $\mathrm{SiO}_{2} @ \mathrm{CA}$ thermal treatment and reaches its maximum for $\mathrm{CDs}$ obtained from $\mathrm{SiO}_{2} @ \mathrm{CDs}-60$ (figures 12(a)-(c)). The PL band symmetry of CDs deteriorates with increasing of the maternal host pore size, reviling short-wavelength shoulder, figure 12(d).

This observation is consistent with those obtained for $\mathrm{SiO}_{2} @ \mathrm{CDs}$ (figure 7) and can indicate the formation of less decarboxylated CDs for short treatment time (less than $60 \mathrm{~min}$ ) in silica gel with larger pores.

Quantum yield was determined for $\mathrm{CDs}$ from $\mathrm{SiO}_{2}$ (d)@CDs-r thermally treated for 60-600 min. The results presented in table 4 demonstrate that the CDs obtained in silica host with narrow pores have higher QY (up to $10.1 \%$ ) than those obtained in larger porous (8.0\%). It seems that prolonged time of the thermal treatment increases QY of CDs, at least for those obtained in silicas with narrower pores. 


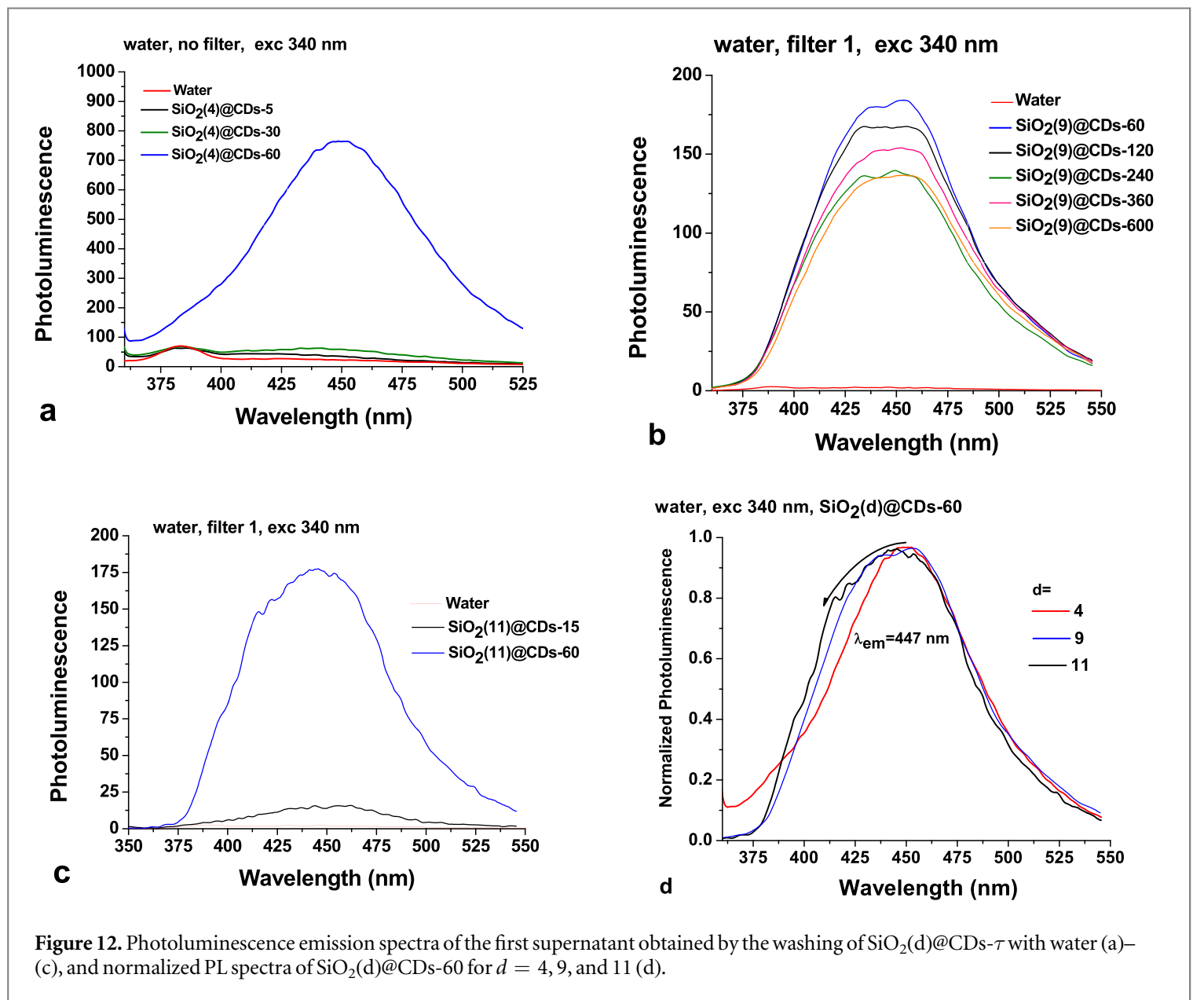

Table 4. Quantum yield of water suspension of CDs, obtained from $\mathrm{SiO}_{2}(\mathrm{~d}) @ \mathrm{CDs}-\mathrm{r}$.

\begin{tabular}{|c|c|c|}
\hline Sample & $\begin{array}{c}\text { QY } \\
\text { (exc.340 nm), \% }\end{array}$ & $\begin{array}{c}\text { QY } \\
\text { (exc. } 350 \mathrm{~nm}), \%\end{array}$ \\
\hline $\mathrm{SiO}_{2}(4) @ \mathrm{CDs}-170-60$ & 7.3 & 5.5 \\
\hline $\mathrm{SiO}_{2}(4) @ \mathrm{CDs}-170-600$ & 10.1 & 7.9 \\
\hline $\mathrm{SiO}_{2}(6) @ \mathrm{CDs}-170-180$ & 6.3 & 4.7 \\
\hline $\mathrm{SiO}_{2}(11) @ \mathrm{CDs}-170-600$ & 8.0 & 5.2 \\
\hline
\end{tabular}

\section{Conclusions}

It was proven that rinsing of $\mathrm{SiO}_{2} @ \mathrm{CA}$ with ether allows manipulating with $\mathrm{CA}$ loading into the host pores. XPS spectra of silica-embedded CDs suggest the formation of partly decarboxylated carbon nanoparticles. In silica gel with larger pores, a short time (less than $100 \mathrm{~min}$ ) of $\mathrm{SiO}_{2} @ \mathrm{CA}$ pyrolysis resulted in the formation of the particles, which exhibit strong blue-shifted PL with a maximum at $420 \mathrm{~nm}$. Increasing of pyrolysis time leads to the formation of luminescent solids with red-shifted $(450 \mathrm{~nm}) \mathrm{PL}$. These particles eluted with water demonstrate PL at $447 \mathrm{~nm}$. Time of $\mathrm{SiO}_{2} @ \mathrm{CA}$ thermal treatment has no visible effect on CDs PL, except those obtained for very short (less than $60 \mathrm{~min}$ ) time of the pyrolysis.

\section{Acknowledgments}

This study was financed in part by the Conselho Nacional de Desenvolvimento Científico e Tecnológico (CNPq) grants nos. 306992/2018-3, 409090/2018-2 and 438450/2018-3. Additionally, the authors are grateful for financial support from Coordenação de Aperfeiçoamento de Pessoal de Nível Superior, CAPES (grant № 2013037-31005012005P5 - PNPD-PUC Rio, Brazil). Albina Mikhraliieva is grateful to CNPq(154820/2015-6) 
and Fundação Carlos Chagas Filho de Amparo à Pesquisa do Estado do Rio de Janeiro (FAPERJ) (E-26/200.612/ 2018) for the conceded fellowships. Prof. Ricardo Aucélio thanks scholarships and grant from FAPERJ (E-26/ 202.912/2017, E-26/010.101131/2018) and CNPq(303866/2017-9). The authors acknowledge utilization of TGM beamline (3D photoluminescence experiment) at Brazilian Synchrotron Light Laboratory (LNLS) from Brazilian Center for Research in Energy and Materials (CNPEM, Proposal № 20170465). Special thanks to Prof. Flávio Garcia and Dr. Richard Caraballo-Vivas for the assistance in the XRD studies (Laboratory of the X-rays diffraction, CBPF, Brazil) and to LABNANO for utilization of electron microscopy facilities (CBPF, Brazil); Brazilian Nanotechnology National Laboratory (LNNano) from CNPEM for technical support in XPS analyses. Also, the authors are grateful to Prof Edilson V. Benvenutti for fruitful help and collaboration.

\section{Data availability}

The raw data required to reproduce these findings are available to download from http:/ / doi.org/10.17632/ 9md6ykhnks.1.

\section{ORCID iDs}

Albina Mikhraliieva (i) https://orcid.org/0000-0003-2403-6692

Vladimir Zaitsev (i) https://orcid.org/0000-0001-5067-3658

Michael Nazarkovsky (ib https://orcid.org/0000-0002-7166-4184

\section{References}

[1] Hu C, Li M, Qiu J and Sun Y-P 2019 Design and fabrication of carbon dots for energy conversion and storage Chem. Soc. Rev. 48 2315-37

[2] Wang L, Yuan Z, Karahan H E, Wang Y, Sui X, Liu F and Chen Y 2019 Nanocarbon materials in water disinfection: State-of-the-art and future directions Nanoscale. 119819-39

[3] Shi X, Wei W, Fu Z, Gao W, Zhang C, Zhao Q, Deng F and Lu X 2019 Review on carbon dots in food safety applications Talanta 194 809-21

[4] Zheng M and Xie Z2019 A carbon dots-based nanoprobe for intracellular Fe3 + detection, Mater Today Chem. 13 121-7

[5] Zhang Y-N, Niu Q, Gu X, Yang N and Zhao G 2019 Recent progress on carbon nanomaterials for the electrochemical detection and removal of environmental pollutants Nanoscale. 11 11992-2014

[6] Devi P, Rajput P, Thakur A, Kim K-H and Kumar P 2019 Recent advances in carbon quantum dot-based sensing of heavy metals in water, TrAC Trends Anal. Chem. 114 171-95

[7] Molaei M J2019 A review on nanostructured carbon quantum dots and their applications in biotechnology, sensors, and chemiluminescence Talanta $196456-78$

[8] Liu C L, W, Sun X, Pan W, Yu G and Wang J 2018 Excitation dependent emission combined with different quenching manners supports carbon dots to achieve multi-mode sensing, Sensors Actuators B Chem. 263 1-9

[9] Mohammadinejad R, Dadashzadeh A, Moghassemi S, Ashrafizadeh M, Dehshahri A, Pardakhty A, Sassan H, Sohrevardi S-M and Mandegary A 2019 Shedding light on gene therapy: carbon dots for the minimally invasive image-guided delivery of plasmids and noncoding RNAs - A review J. Adv. Res. 18 81-93

[10] Anwar S et al 2019 Recent advances in synthesis, optical properties, and biomedical applications of carbon dots ACS Appl. Bio Mater. 2 2317-38

[11] Omstead D T, Sjoerdsma J and Bilgicer B 2019 Polyvalent nanoobjects for precision diagnostics Annu. Rev. Anal. Chem. 12 69-88

[12] Wu P-C et al 2018 Efficient two-photon luminescence for cellular imaging using biocompatible nitrogen-doped graphene quantum dots conjugated with polymers Nanoscale. 10 109-17

[13] Pirsaheb M, Mohammadi S, Salimi A and Payandeh M 2019 Functionalized fluorescent carbon nanostructures for targeted imaging of cancer cells: a review Microchim. Acta 186231

[14] Kumawat M K, Thakur M, Gurung R B and Srivastava R 2017 Graphene quantum dots for cell proliferation, nucleus imaging, and photoluminescent sensing applications Sci. Rep. 7 1-16

[15] Pirsaheb M, Mohammadi S and Salimi A 2019 Current advances of carbon dots based biosensors for tumor marker detection, cancer cells analysis and bioimaging TrAC-Trends Anal. Chem. $11583-99$

[16] Yuan Y, Guo B, Hao L, Liu N, Lin Y, Guo W, Li X and Gu B 2017 Doxorubicin-loaded environmentally friendly carbon dots as a novel drug delivery system for nucleus targeted cancer therapy Colloids Surfaces B Biointerfaces. 159 349-59

[17] Boakye-Yiadom K O et al 2019 Carbon dots: Applications in bioimaging and theranostics Int. J. Pharm. 564308-17

[18] Lu D, Tao R and Wang Z 2019 Carbon-based materials for photodynamic therapy: A mini-review Front. Chem. Sci. Eng. 13 310-23

[19] Xu X, Ray R, Gu Y, Ploehn H J, Gearheart L, Raker K and Scrivens W A 2004 Electrophoretic analysis and purification of fluorescent single-walled carbon nanotube fragments J. Am. Chem. Soc. 126 12736-12737

[20] Shinde D B and Pillai V K 2012 Electrochemical preparation of luminescent graphene quantum dots from multiwalled carbon nanotubes Chem.-A Eur.J. 18 12522-8

[21] Wang Q, Zheng H, Long Y, Zhang L, Gao M and Bai W 2011 Microwave-hydrothermal synthesis of fluorescent carbon dots from graphite oxide Carbon N. Y. 49 3134-40

[22] Zhang X, Wang S, Zhu C, Liu M, Ji Y, Feng L, Tao L and Wei Y 2013 Carbon-dots derived from nanodiamond: Photoluminescence tunable nanoparticles for cell imaging J. Colloid Interface Sci. 397 39-44

[23] Li X, Wang H, Shimizu Y, Pyatenko A, Kawaguchi Kand Koshizaki N 2011 Preparation of carbon quantum dots with tunable photoluminescence by rapid laser passivation in ordinary organic solvents Chem. Commun. 47 932-4 
[24] Yuan F, Ding L, Li Y, Li X, Fan L, Zhou S, Fang D and Yang S 2015 Multicolor fluorescent graphene quantum dots colorimetrically responsive to all-pH and a wide temperature range Nanoscale. 7 11727-33

[25] Liu H, Ye T and Mao C 2007 Fluorescent carbon nanoparticles derived from candle soot, angew Chemie Int. Ed. 46 6473-5

[26] Sun Y-P et al 2006 Quantum-sized carbon dots for bright and colorful photoluminescence J. Am. Chem. Soc. 128 7756-7

[27] Hu S-L, Niu K-Y, Sun J, Yang J, Zhao N-Q and Du X-W 2009 One-step synthesis of fluorescent carbon nanoparticles by laser irradiation J. Mater. Chem. 19484-8

[28] Zhu S, Zhao X, Song Y, Lu S and Yang B 2016 Beyond bottom-up carbon nanodots: citric-acid derived organic molecules Nano Today. $11128-32$

[29] Song Y, Zhu S, Zhang S, Fu Y, Wang L, Zhao X and Yang B 2015 Investigation from chemical structure to photoluminescent mechanism: A type of carbon dots from the pyrolysis of citric acid and an amine J. Mater. Chem. C. 35976-84

[30] Chu K-W, Lee S L, Chang C-J and Liu L 2019 Recent progress of carbon dot precursors and photocatalysis applications Polymers (Basel). 11689

[31] Li H, Kang Z, Liu Y and Lee S-T T 2012 Carbon nanodots: synthesis, properties and applications J. Mater. Chem. 22 24230-53

[32] Lim SY, Shen W and Gao Z 2015 Carbon quantum dots and their applications Chem. Soc. Rev. 44362-81

[33] Lu Y, Zhang L and Lin H 2014 The use of a microreactor for rapid screening of the reaction conditions and investigation of the photoluminescence mechanism of carbon dots Chem.-A Eur. J. 20 4246-50

[34] Bin Chen B, Liu M L, Li C M and Huang C Z 2019 Fluorescent carbon dots functionalization Adv. Colloid Interface Sci. 270 165-90

[35] Essner J B, Kist J A, Polo-Parada L and Baker G A 2018 Artifacts and errors associated with the ubiquitous presence of fluorescent impurities in carbon nanodots Chem. Mater. 30 1878-87

[36] Fuyuno N, Kozawa D, Miyauchi Y, Mouri S, Kitaura R, Shinohara H, Yasuda T, Komatsu N and Matsuda K 2013 Size-dependent luminescence properties of chromatographically-separated graphene quantum dots ArXiv. 1311 1684 (https://arxiv.org/abs/ 1311.1684)

[37] Zhu X, Zuo X, Hu R, Xiao X, Liang Y and Nan J 2014 Hydrothermal synthesis of two photoluminescent nitrogen-doped graphene quantum dots emitted green and khaki luminescence Mater. Chem. Phys. 147 963-7

[38] Bao L, Zhang Z L, Tian Z Q, Zhang L, Liu C, Lin Y, Qi B and Pang D W 2011 Electrochemical tuning of luminescent carbon nanodots: From preparation to luminescence mechanism Adv. Mater. 23 5801-6

[39] Dong Y, Zhou N, Lin X, Lin J, Chi Y and Chen G 2010 Extraction of electrochemiluminescent oxidized carbon quantum dots from activated carbon Chem. Mater. 22 5895-9

[40] Ding H, Yu S B, Wei J S and Xiong H M 2016 Full-color light-emitting carbon dots with a surface-state-controlled luminescence mechanism ACS Nano. 10 484-91

[41] Zong J et al 2011 Synthesis of photoluminescent carbogenic dots using mesoporous silica spheres as nanoreactors Chem. Commun. 47 764-6

[42] Baldovi H G, Valencia S, Alvaro M, Asiri A M and Garcia H 2015 Highly fluorescent C-dots obtained by pyrolysis of quaternary ammonium ions trapped in all-silica ITQ-29 zeolite Nanoscale. 7 1744-52

[43] Liu J, Zhang H, Wang N, Yu Y, Cui Y, Li J and Yu J 2019 Template-modulated afterglow of carbon dots in zeolites: room-temperature phosphorescence and thermally activated delayed fluorescence ACS Mater. Lett. 158-63

[44] Xu H, Zhou S, Xiao L, Li S, Song T, Wang Y and Yuan Q 2015 Nanoreactor-confined synthesis and separation of yellow-luminescent graphene quantum dots with a recyclable SBA-15 template and their application for Fe(III) sensing Carbon N. Y. 87 215-25

[45] Xu H, Zhou S, Liu J and Wei Y 2018 Nanospace-confined preparation of uniform nitrogen-doped graphene quantum dots for highly selective fluorescence dual-function determination of Fe $3+$ and ascorbic acid RSC Adv. 85500-8

[46] Kurdyukov D A, Eurov D A, Stovpiaga E Y, Kirilenko D A, Konyakhin S V, Shvidchenko A V and Golubev V G 2016 Template synthesis of monodisperse carbon nanodots Phys. Solid State 58 2545-9

[47] Ortega-Liebana M C, Chung N X, Limpens R, Gomez L, Hueso J L, Santamaria J and Gregorkiewicz T 2017 Uniform luminescent carbon nanodots prepared by rapid pyrolysis of organic precursors confined within nanoporous templating structures Carbon N. Y. $117437-46$

[48] Nelson D K, Razbirin B S, Starukhin A N, Eurov D A, Kurdyukov D A, Stovpiaga E Y and Golubev V G 2016 Photoluminescence of carbon dots from mesoporous silica Opt. Mater. (Amst). 59 28-33

[49] Hayashi K et al 2019 Pyrolytic production of fluorescent pyrone derivatives produced in the confined space of super-microporous silicas Bull. Chem. Soc. Jpn. 92 1170-4

[50] Tian Y, Ran Z and Yang W 2017 Carbon dot-silica composite nanoparticle: an excitation-independent fluorescence material with tunable fluorescence RSC Adv. 7 43839-44

[51] Kurdyukov D A et al 2018 Controllable spherical aggregation of monodisperse carbon nanodots Nanoscale. 10 13223-35

[52] Nguyen C and Do D D 1999 A New Method for the Characterization Of Porous Materials Langmuir 15 3608-15

[53] Nguyen C and Do D D 2000 Effects of Probing Vapors and Temperature on the Characterization of Micro-Mesopore Size Distribution of Carbonaceous Materials Langmuir 16 7218-22

[54] Gun'ko Vladimir M and Do Duong D 2001 Characterisation of pore structure of carbon adsorbents using regularisation procedure Colloids and Surfaces A: Physicochemical and Engineering Aspects 193 71-83

[55] Gun'ko Vladimir M. 2014 Composite materials: Textural characteristics Applied Surface Science 307 444-54

[56] Zhu S, Meng Q, Wang L, Zhang J, Song Y, Jin H, Zhang K, Sun H, Wang H and Yang B 2013 Highly photoluminescent carbon dots for multicolor patterning sensors, and bioimaging, Angew. Chemie - Int. Ed. 52 3953-7

[57] Dong Y, Shao J, Chen C, Li H, Wang R, Chi Y, Lin X and Chen G 2012 Blue luminescent graphene quantum dots and graphene oxide prepared by tuning the carbonization degree of citric acid Carbon N. Y. 50 4738-43

[58] Yuan T, Meng T, He P, Shi Y, Li Y, Li X, Fan L and Yang S 2019 Carbon quantum dots: an emerging material for optoelectronic applications J. Mater. Chem. C. $76820-35$

[59] Liu R, Wu D, Liu S, Koynov K, Knoll W, Li Q, Liu S, Li Q, Liu R and Koynov K 2009 An Aqueous Route to Multicolor Photoluminescent Carbon Dots Using Silica Spheres as Carriers, Angew. Chemie Int. Ed. 48 4598-601

[60] Liu M L, Bin Chen B, Li C M and Huang C Z 2019 Carbon dots: Synthesis, formation mechanism, fluorescence origin and sensing applications Green Chem. 21 449-71 